\title{
Pola Distribusi Aboveground Biomass Kawasan Hutan Mangrove Peniti Kalimantan Barat
}

\author{
Rafdinal $^{\bowtie}$, Rizalinda, dan Sukal Minsas
}

Jurusan Biologi FMIPA, Univesitas Tanjungpura Pontianak, Kalimantan Barat

\section{Info Artikel Abstract}

Diterima: 1 Maret 2019

Disetujui: 30 Maret 2019

Dipublikasikan: 25 April 2019

Keywords:

aboveground biomass,

Mangrove, mangrove Peniti

Kalimantan Barat

This study aims to analyze the distribution pattern of aboveground biomass (AGB) in the mangrove ecosystem of West Kalimantan Safety. In addition, it also analyzes the differences in biomass and carbon stocks in the condition of mangrove forests. The study of the distribution pattern of AGB of mangrove forests was carried out between August and September 2018. Determination of the location of the study was based on a conceptual approach in the dimensions of spatial temporal that is using the Porposive Random Sampling method. Vegetation analysis was carried out by a single plot measuring $50 \mathrm{~m} \times 50 \mathrm{~m}$ at each selected location. Based on vegetation analysis data it was found that the density of mangrove stands on the Peniti coast ranged from 38 to $185 \mathrm{ind} / \mathrm{ha}$, with an average of $88.25 \pm 66.15 \mathrm{ind}$. / Ha. The AGB of pinch mangrove forests ranged from 8.85 to $84.82 \mathrm{Mg} /$ ha with the largest total $A G B$ distributed in the stand diameter class of more than $80 \mathrm{~cm}$.

\begin{abstract}
Abstrak
Penelitian ini bertujuan untuk menganalisis pola distribusi aboveground biomass (AGB) pada ekosistem mangrove Peniti Kalimantan Barat. Selain itu juga untuk menganalisis perbedaan biomassa, dan cadangan karbon pada kondisi hutan mangrove. Kajian pola distribusi AGB hutan mangrove Peniti dilakukan antara bulan Agustus dan September 2018. Penentuan lokasi penelitian didasarkan pada pendekatan konseptual dalam dimensi spasio temporal yaitu menggunakan metode Porposive Random Sampling. Analisis vegetasi dilakukan dengan metode petak tunggal berukuran $50 \mathrm{~m} \times 50 \mathrm{~m}$ pada setiap lokasi terpilih. Berdasarkan data analisis vegetasi didapatkan bahwa kerapatan tegakan mangrove di pesisir Peniti berkisar antara 38 sampai 185 ind/ha, dengan rata-rata $88,25 \pm 66,15$ ind./ha. AGB tegakan hutan mangrove Peniti berkisar antara 8,85 sampai $84,82 \mathrm{Mg} / \mathrm{ha}$ dengan total AGB terbesar terdistribusi pada kelas diameter tegakan lebih dari 80 $\mathrm{cm}$.
\end{abstract}

(C) 2019 Universitas Negeri Semarang

$凶$ Alamat korespondensi:

p-ISSN 2252-6277

Jurusan Biologi FMIPA, Univesitas Tanjungpura Pontianak

e-ISSN 2528-5009

E-mail: rafdinal.mipa@gmail.com 


\section{PENDAHULUAN}

Hutan mangrove merupakan salah satu jenis ekosistem khas yang banyak dijumpai di Indonesia, sebagai ciri negara kepulauan yang memiliki garis pantai yang luas. Di Indonesia perkiraan luas mangrove cukup beragam, menurut Dit. Bina Program INTAG pada tahun 1996 luas mangrove di Indonesia adalah sebesar 3,5 juta hektar. Sedangkan berdasarkan data tahun 1999 diperkirakan luas hutan mangrove Indonesia mencapai 8,60 juta hektar dan 5,30 juta hektar di antaranya dalam kondisi rusak (DitJend Rehabilitasi Lahan dan Perhutanan Sosial, 2001).

Hutan mangrove secara ekonomis dimanfaatkan masyarakat sebagai sumber bahan bakar (kayu, arang), bahan bangunan (balok, papan), bahan tekstil, makanan, dan obat-obatan. Selain itu hutan mangrove memiliki fungsi ekologis dalam menjaga kondisi pantai agar tetap stabil, melindungi tebing pantai dan tebing sungai, mencegah terjadinya abrasi dan intrusi air laut, serta sebagai habitat benih ikan, udang, dan kepiting untuk hidup dalam mencari makan (Gunarto, 2004; Rusila et al., 1999).

Mangrove merupakan salah satu parameter blue carbon, karena perannya dalam memanfaatkan $\mathrm{CO}_{2}$ untuk fotosintesis dan menyimpannya dalam bentuk biomassa dan di dalam sedimen. Menurut Kauffman \& Daniel (2012), simpanan karbon di hutan mangrove lebih tinggi dibandingkan simpanan karbon pada tipe hutan lainnya, dimana simpanan karbon terbesar terdapat pada sedimen mangrove. Daun dan ranting pohon mangrove yang gugur didekomposisi oleh mikroorganisme, dan menjadi salah satu sumber bahan organik pada sedimen mangrove

Kawasan hutan mangrove Kabupaten Mempawah berada di sepanjang pesisir sebelah barat Kabupaten Mempawah, Kalimantan Barat. Kawasan ini merupakan sumber daya alam yang sangat penting, memiliki manfaat baik secara langsung maupun tidak langsung terhadap masyarakat sekitar. Manfaat langsung keberadaan pesisir hutan mangrove Kabupaten Mempawah di antaranya adalah kayu, hasil hutan bukan kayu dan satwa. Sedangkan manfaat tidak langsungnya adalah berupa jasa lingkungan, baik sebagai pengatur tata air, fungsi estetika, maupun sebagai penyedia oksigen dan penyerap karbon.

Menurunnya kualitas dan kuantitas hutan mangrove di daerah Kabupaten Mempawah telah mengakibatkan berbagai dampak yang sangat mengkhawatirkan, seperti berkurangnya hasil penangkapan nelayan, abrasi, dan semakin jauhnya intrusi air laut jauh kearah pantai. Hal yang sama juga terjadi pada beberapa wilayah di sepanjang pantai Kalimantan Barat. Rafdinal \& Nofrita (2004) melaporkan bahwa terjadinya kerusakan hutan mangrove di wilayah pesisir Peniti telah menyebabkan berkurangnya hasil tangkapan perikanan penduduk seperti kepah (Polymesoda bengalensis) dan kepiting bakau (Scylla serrata). Salah satu penyebabnya adalah karena pemanfaatan kawasan mangrove yang tidak didasarkan pada kondisi daya dukungnya.

Penelitian ini bertujuan untuk menganalisis pola distribusi aboveground biomass pada ekosistem mangrove Peniti Kalimantan Barat. Selain itu juga untuk menganalisis perbedaan biomassa, dan cadangan karbon pada kondisi hutan mangrove yang diteliti. Hasil penelitian ini bermaanfaat dalam memberikan informasi mengenai potensi menyimpan karbon pada ekosistem mangrove, sehingga data 
tersebut dapat menjadi bahan acuan dalam pembuatan kebijakan tentang pengelolaan, perlindungan serta pelestarian mangrove bagi instansi pemerintah terkait.

\section{METODE}

\section{Deskripsi Daerah Penelitian}

Penelitian ini telah dilaksanakan mulai dari bulan September 2017, di kawasan muara Sungai Peniti Kabupaten Pontianak. Identifikasi dan analisis data dilakukan di Laboratorium Biologi FMIPA UNTAN. Lokasi penelitian adalah perairan kawasan hutan mangrove Peniti Kalimantan Barat. Jarak lokasi penelitian dari kota Pontianak $\pm 35 \mathrm{~km}$ atau 1 jam 15 menit perjalanan dengan mempergunakan kendaraan umum. Kawasan ini terletak antara $0^{\circ} 30^{\prime}$ Lintang Utara dan $0^{\circ} 17^{\prime}$ Lintang Selatan serta antara $100^{\circ} 24^{\prime}$ Bujur Timur. Sebelah Barat kawasan ini berbatasan dengan Laut Natuna, sebelah utara berbatasan dengan desa Sungai Burung, sebelah selatan dengan desa Sungai Nipah, dan sebelah timur berbatasan dengan Peniti Dalam atau Jungkat.

Menurut klasifikasi iklim Schmidt dan Ferguson, kawasan Peniti termasuk dalam tipe iklim A dan daerah basah dengan suhu berkisar antar $20^{\circ} \mathrm{C}-34^{\circ} \mathrm{C}$. Curah hujan cukup besar antara 2000-3000 $\mathrm{mm}$ dengan hari hujan 80-200 hari setahun. Kondisi kawasan hutan mangrove Peniti sangat dipengaruhi oleh adanya pasang surut air laut dan aliran sungai disekitarnya. Pasang surut di daerah ini adalah pasang surut campuran dengan dominasi semi harian, yaitu dalam satu hari terdapat 2 kali pasang dan 2 kali surut. Pada saat air laut pasang naik, aliran air dari arah barat (laut natuna) masuk menuju estuari sungai Peniti dan kawasan bakau lainnya, sedangkan pada saat surut aliran air dari sungai-sungai di sekitarnya masuk ke estuari sungai Peniti menuju Laut Natuna.

\section{Penentuan Sampling Pengamatan}

Penentuan lokasi penelitian didasarkan pada pendekatan konseptual dalam dimensi spasio temporal yaitu menggunakan metode Porposive Random Sampling. Berdasarkan kondisi tersebut ditetapkan ada 3 lokasi pengamatan vegetasi mangrove di kawasan hutan mangrove Peniti Kalimantan Barat. Ketiga lokasi pengamatan tersebut adalah kawasan mangrove Tanjung Laut, Sungai Kasim Purun, dan Palau Tanjung. Pengambilan data penelitian pada setiap lokasi pengamatan dilakukan dengan analisis vegetasi. Analisis vegetasi dilakukan dengan metoda petak tunggal berukuran $50 \mathrm{~m}$ x $50 \mathrm{~m}$ pada setiap lokasi terpilih. Di dalam setiap PU secara nested sampling dibuat sub-sub PU berukuran $10 \mathrm{~m} \mathrm{x}$ $10 \mathrm{~m}$. Pada setiap sub-PU dilakukan identifikasi jenis dan dicatat jumlah setiap jenisnya, dan diukur diameter setiap individu pohon. Pengukuran kerapatan dan basal area tegakan mengacu pada perhitungan Mueller-Dombois and Ellenberg (1974) dengan formula sebagai berikut.

$$
\text { Kerapatan }(K)=\frac{\text { Jumlah individu suatu jenis }}{\text { Luas petak contoh }}
$$

Basal area $\quad=3,14 \mathrm{r} 2$ 


\section{Pendugaan Aboveground Biomass (Biomasa Atas Permukaan)}

Pengukuran biomasa atas permukaan (aboveground biomass/AGB) tegakan dilakukan dengan metode non destruktif. Pendugaan AGB didasarkan pada data individu yang terdapat pada petak contoh. Dari data tegakan yang terdapat pada masing masing lokasi selanjutnya dikelompokkan kedalam lima kelas diameter (KD) pohon. Pengelompokan didasarkan pada kelas diameter $<20 \mathrm{~cm} ; 20,1-40 \mathrm{~cm} ; 40,1$ $60 \mathrm{~cm} ; 60,1-80 \mathrm{~cm}$; dan $>80 \mathrm{~cm}$. Pendugaan biomasa aboveground pohon (aboveground tree biomassa) dilakukan dengan menggunakan persamaan alometrik Komiyama et al. (2008).

$$
\text { Wtop }=0,251 \rho \mathrm{D} 2,46
$$

Dimana:

Wtop : biomasa atas permukaan (aboveground biomass)

$\rho \quad$ : berat jenis kayu

D : diameter pohon

\section{Pendugaan Karbon Tegakan}

Cadangan karbon AGB dihitung berdasaarkan asumsi bahwa cadangan karbon berisikan 50\% dari total AGB (Brown \& Lugo, 1982; Cannel, 1995; Richter et al. 1995; Schroeder, 1992).

\section{Analisis Data}

Analisis keragaman satu arah (ANOVA) digunakan untuk membandingkan perbedaaan jumalah kerapatan tegakan dan biomasa per periode pengamatan dan lokasi penelitian dengan menggunakan program komputer SPSS. Uji beda jujur (Honest Signifsicant Difference, HSD) TukeyKramer digunakan untuk membandingkan besarnya perbedaan. Adanya perbedaan dievaluasi menggunakan selang kepercayaan 5\% $(\mathrm{P}<0.05)$.

\section{HASIL DAN PEMBAHASAN}

\section{Karakteristik Tegakan Hutan Mangrove Peniti}

Berdasarkan hasil penelitian komposisi tegakan hutan mangrove Peniti telah ditemukan ada 16 jenis tumbuhan mangrove. Berdasarkan pengelompokkan jenis mangrove oleh Tomlison (1994), tumbuhan mangrove yang dijumpai tersebut terdiri dari 7 jenis mangrove sejati, 3 jenis mangrove pendukung, dan 6 jenis mangrove asosiasi. Hasil analisis vegetasi yang dalam petak pengamatan pada masing-masing lokasi pengamatan telah ditemukan 3 jenis tumbuhan mangrove sejati, yaitu Avicennia officinalis, Bruguira cylindrica, dan Sonneratia caseolaris.

Bila dibandingkan dengan hasil penelitian Rafdinal et al. (2016), komposisi jenis tegakan mangrove Peniti tidak menunjukan perubahan dari sudut jenis-jenis penyusunnya. Umumnya jenis-jenis tegakan mangrove yang ditemukan Rafdinal et al. (2016) masih ditemukan pada penelitian ini (2017). Ditinjau dari aspek jenis penyusun tegakan hutan mangrove Peniti memperlihatkan heterogenitas jenis yang sangat rendah. Hal ini terlihat dari 89,99\% mangrove di hutan Peniti didominasi oleh genus $A$. officinalis. Penyusun vegetasi tegakan mangrove Peniti jika dibandingkan dengan penelitian lain, seperti pada penelitian Tang et al. (2016) pada kawasan mangrove di Kabupaten Konawe Selatan, Provinsi 
Sulawesi Tenggara. Zamroni \& Rohyani (2008) melaporkan pada kawasan hutan mangrove di Teluk Sepi menunjukkan perbedaan terkait jenis-jenis penyusun kawasan hutan mangrove. Perbandingan jenis penyusun vegetasi mangrove Peniti dengan berbagai lokasi yang berbeda tersaji dalam Tabel 1.

Tabel 1. Perbandingan Produksi Serasah (Litterfall) pada Lokasi yang Berbeda

\begin{tabular}{|c|c|}
\hline Lokasi & Jenis Penyusun \\
\hline Konawe Selatan, Sulawesi Tenggara & Rhizophora apiculata, Bruguiera gymnorrhiza ${ }^{1}$ \\
\hline Kabupaten Pesawaran & Rhizophora sp. ${ }^{2}$ \\
\hline Kabupaten Tangerang, Banten & $\begin{array}{l}\text { Avicenia marina, Avicenia alba, Rhizophora mucronata, dan } \\
\text { Sonneratia caseolaris }\end{array}$ \\
\hline Pantai Teluk Sepi, Lombok Barat & $\begin{array}{l}R \text {. apiculata, } R \text {. mucronata, } R \text {. stylosa, Sonneratia alba dan } \\
\text { Aegiceras corniculatum }{ }^{4} \text {. }\end{array}$ \\
\hline Tanjung Api-Api, Sumatera Selatan & A. marina dan $S$. Caseolaris ${ }^{5}$ \\
\hline Teluk Bintuni, Papua & Rhizophora sp. dan Bruguiera sp. ${ }^{6}$ \\
\hline Teluk Benoa, Bali & Rhizophora apiculata ${ }^{7}$ \\
\hline Peninsular, Malaysia & R. mucronata dan $R$. Apiculata ${ }^{8}$ \\
\hline Kabupaten Mempawah, Kalbar & Avicennia officinalis \\
\hline
\end{tabular}

Referensi: 1) Tang et al., 2016, 2) Andrianto et al., 2015, 3) Aida et al., 2014, 4) Zamroni \& Rohyani, 2008, 5) Ulqodry, 2008, 6) Pribadi, R., 1998, 7) Kitamura et al., 1998, 8) Ashton et al., 1999, 9) This Study, 2018

Kerapatan tegakan mangrove $(>20 \mathrm{~cm} \mathrm{dbh}$ ) berdasarkan lokasi pengamatan ditemukan bahwa kerapatan tegakan mangrove Tanjung laut lebih tinggi (185 ind/ha) dibanding lokasi Kasim Purun (56 ind/ha) dan Pulau Tanjung (38 ind/ha). Berdasarkan jenis, kepadatan A. officinalis merupakan tegakan mangrove yang mendominasi pada semua lokasi penelitian. Basal area tegakan mangrove di lokasi Tanjung laut (55,16 $\mathrm{m}^{2} / \mathrm{ha}$ ) lebih tinggi dibandingkan lokasi Kasim purun dan Pulau Tanjung (Tabel 2).

Tabel 2. Karakteristik Struktural Kondisi Kawasan Hutan Mangrove Peniti

\begin{tabular}{lccc}
\hline \multicolumn{1}{c}{ Variabel } & \multicolumn{3}{c}{ Lokasi } \\
\cline { 2 - 4 } & Tj. Laut & Kasim Purun & Pulau Tanjung \\
\hline Kekayaan species & 5 & 5 & 5 \\
Kerapatan tegakan (ind/ha) & 185 & 56 & 38 \\
Kerapatan species dominan (ind/ha) & & & \\
$\quad$ Avicennia officinalis & 183 & 56 & 16 \\
$\quad$ Bruguira cylindrica & - & - & 1 \\
$\quad$ Sonneratia caseolaris & - & - & 1.18 \\
Basal area $\left(\mathrm{m}^{2} /\right.$ ha & 55,16 & 13,34 & \\
\hline
\end{tabular}

\section{Distribusi AGB Tegakan Hutan Mangrove Peniti}

Estimasi AGB tegakan di kawasan hutan mangrove Peniti berdasarkan pendekatan persamaan Alometrik Komiyama et al. (2008) dapat dilihat pada Gambar 1. Hasil analisis estimasi AGB mendapatkan rata-rata AGB tegakan mangrove Peniti sebesar 34,22 Mg/ha. Berdasarkan pengujian statistic One Way Anova menunjukan bahwa ada perbedaan yang signifikan antar biomasa yang terdapat di ketiga lokasi hutan mangrove Peniti $(\mathrm{P}<0,05$; One Way Anova $)$. 


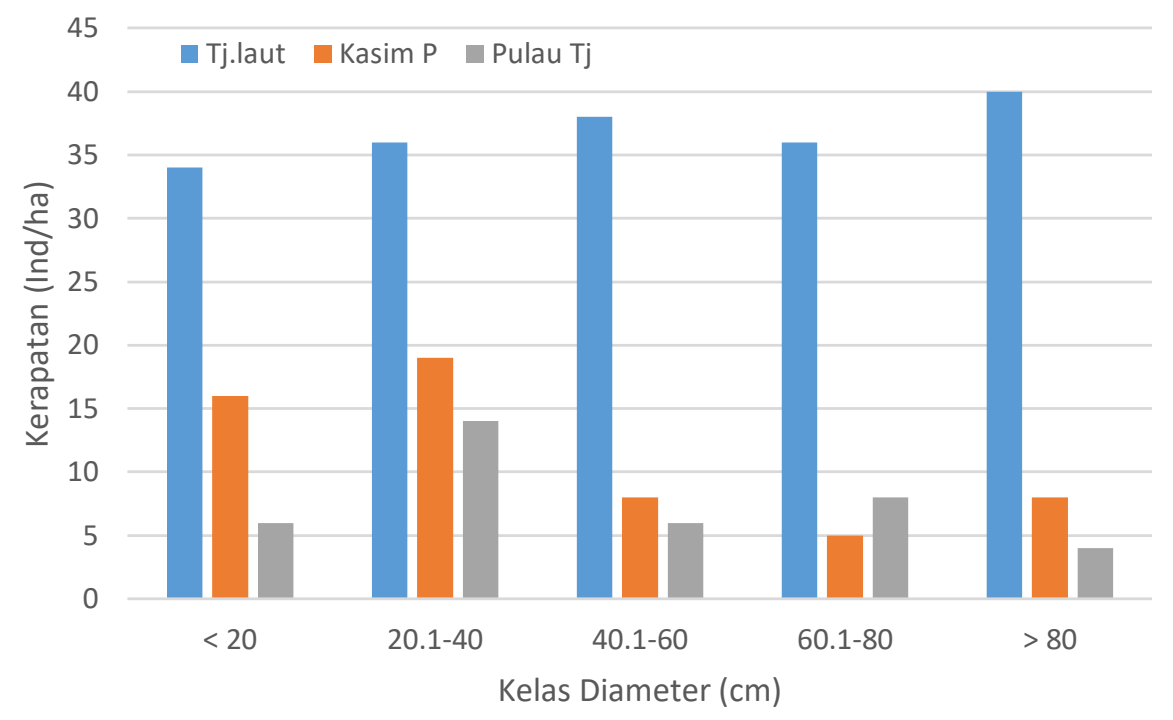

Gambar 1. Kerapatan tegakan mangrove berdasarkan kelas diameter (cm) di kawasan Peniti Kalimantan Barat

Dari total masing-masing AGB pada masing-masing lokasi, kontribusi tertingi dari total AGB di hutan mangrove Peniti ditentukan oleh lokasi Tanjung Laut $(84,82 \mathrm{Mg} / \mathrm{ha})$, kemudian dilanjutkan lokasi Kasim Purun (23,74 Mg/ha), dan lokasi Pulau Tanjung (19,46 Mg/ha). Tanjung Laut jauh lebih besar dibanding lokasi lain di hutan mangrove Peniti. Adanya perbedaan total AGB diketiga lokasi tersebut disebabkan refleksi dari perbedaan kerapatan tegakan dan basal area tegakan. Disamping itu banyaknya tegakan dengan ukuran besar di lokasi $\mathrm{Tj}$. Laut dibanding lokasi lain menjadi faktor penentu tingginya total AGB di Tj. Laut. Meskipun individu tegakan mangrove lebih banyak pada kelas diameter di bawah $40 \mathrm{~cm}$ berdasarkan kerapatan tegakan (Gambar 1), namun akumulasi AGB sebagian besar ditemukan pada kelas diameter di atas $80 \mathrm{~cm}$ (Gambar 2).

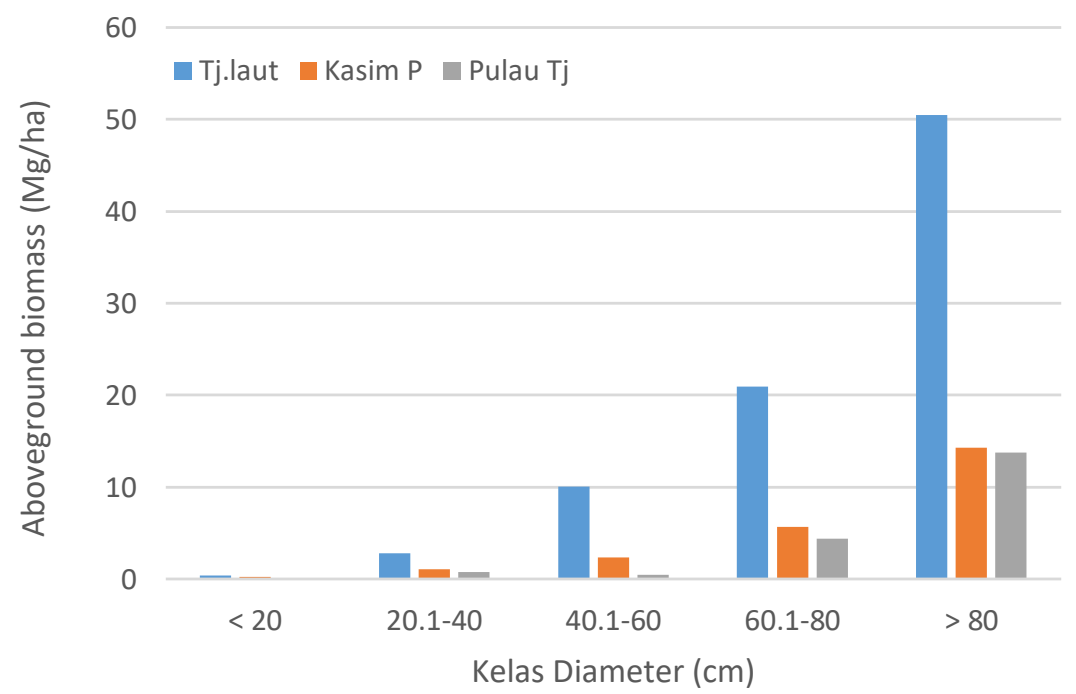

Gambar 2. Aboveground biomass tegakan mangrove berdasarkan kelas diameter di kawasan Peniti Kalimantan Barat 


\section{Total AGB dan Cadangan Karbon Tegakan Hutan Mangrove Peniti}

Berdasarkan total AGB, cadangan karbon AGB kawasan hutan Peniti berkisar antara 4,43-42,41 dengan rata-rata 17,11 Mg C/ha. Pada lokasi $\mathrm{Tj}$. Laut didapatkan cadangan karbon sebesar 42,41 Mg C/ha. Pada lokasi Kasim Purun sebesar 11,87 Mg C/ha, dan Pulau Tanjung sebesar 9,73 Mg C/ha. Dari rata-rata cadangan karbon di ke tiga lokasi tersebut memperlihatkan bahwa total cadangan karbon AGB kawasan mangrove Peniti lebih kecil bila dibandingkan dengan beberapa penelitian seperti Ditha et al. (2014) di kawasan Pesisir muara Gembong Bekasi, Farida et al. (2012) di Marina Bay Malaysia dan lebih tinggi dari penelitian Gupta \& Ghose (2014) di Sundarbans mangrove Swams, India. Ditha et al. (2007) melaporkan cadangan karbon AGB di kawasan Pesisir muara Gembong Bekasi, sebesar 55,39 ton C/ha, Farida et al. (2012) di Marina Bay Malaysia sebesar 98 ton C/ha, sedangkan Gupta and Ghose (2014) melaporkan cadangan karbon AGB di Sundarbans mangrove Swams, India sebesar 8,9-50,9 ton C/ha. Adanya perbedaan cadangan karbon AGB di beberapa kawasan hutan diatas terkait dengan kondisi hutan dan juga besarnya tekanan atau gangguan terhadap vegetasi hutan.

Tabel 3. Perbandingan Persentase Kepadatan dan Potensi Cadangan Karbon Berdasarkan Kelas Diameter $(\geq 8 \mathrm{~cm}, \mathrm{dbh})$

\begin{tabular}{ccccccc}
\hline \multirow{2}{*}{$\begin{array}{c}\text { Kelas Diameter } \\
\mathbf{( \% )}\end{array}$} & \multicolumn{2}{c}{ Tj. Laut } & \multicolumn{2}{c}{ Kp. Purun } & \multicolumn{2}{c}{ P. Tanjung } \\
\cline { 2 - 7 } & $\begin{array}{c}\text { Kerapatan } \\
\mathbf{( \% )}\end{array}$ & $\begin{array}{c}\text { Karbon } \\
\mathbf{( \% )}\end{array}$ & $\begin{array}{c}\text { Kerapatan } \\
\mathbf{( \% )}\end{array}$ & $\begin{array}{c}\text { Karbon } \\
\mathbf{( \% )}\end{array}$ & $\begin{array}{c}\text { Kerapatan } \\
(\mathbf{\%})\end{array}$ & $\begin{array}{c}\text { Karbon } \\
\mathbf{( \% )}\end{array}$ \\
\hline 20,0 & 18,38 & 0,52 & 28,57 & 1,18 & 15,79 & 0,34 \\
$20,1-40$ & 19,46 & 3,35 & 32,14 & 4,55 & 36,84 & 3,85 \\
$40,1-60$ & 20,54 & 11,91 & 14,29 & 10,03 & 15,79 & 2,42 \\
$60,1-80$ & 19,46 & 24,69 & 10,71 & 24,09 & 21,05 & 22,64 \\
$>80$ & 22,16 & 59,54 & 14,29 & 60,15 & 10,53 & 70,75 \\
\hline
\end{tabular}

Dari total cadangan karbon AGB di ketiga lokasi memperlihatkan bahwa total cadangan karbon AGB terdistribusi pada kelas diameter tegakan kecil sampai kelas diameter lebih dari $80 \mathrm{~cm}$. Persentase cadangan karbon AGB terbesar di lokasi Tj. Laut 59,54 \% sangat ditentukan oleh tegakan yang memiliki ukuran kelas diameter besar dari $80 \mathrm{~cm}$, kemudian 24,69\% ditentukan oleh tegakan yang berukuran kelas diameter 60,1-80 cm. Pada lokasi Kasim Purun, kontribusi prosentase cadangan karbon AGB terbesar ditentukan oleh tegakan yang berukuran $>80 \mathrm{~cm}(60,15 \%)$, kemudian $24,09 \%$ ditentukan oleh tegakan yang berukuran kelas diameter 60,1-80 cm . Gambaran lainnya dapat dilihat pada Tabel 3.

\section{SIMPULAN}

Hasil penelitian dapat disimpulkan bahwa pola distribusi biomasa di kawasan vegetasi mangrove umumnya terdisribusi pada kelas diameter di atas $80 \mathrm{~cm}$, dan tingginya cadangan karbon di kawasan hutan mangrove Peniti sangat ditentukan oleh ukuran diameter dan kerapatan tegakan. Jika ukuran tegakan besar dan kerapatan tegakan besar memberikan konsekwensi terhadap tingginya cadangan karbon di kawasan hutan mangrove. 


\section{DAFTAR PUSTAKA}

Aida, G.R., Wardiatno, Y., Fahrudim, A. \& Kamal, M.M. (2014). Produksi serasah mangrove di pesisir Tangerang, Banten (Litterfall production of mangrove in tangerang coastal area, Banten). JIPI, 19(2), 91-97.

Andrianto, F., Bintoro, A. \& Yuwono, S.B. (2015). Produksi dan laju dekomposisi serasah mangrove (Rhizophora sp.) di Desa Durian dan Desa Batu Menyan Kecamatan Padang Cermin Kabupaten Pesawaran. Jurnal Sylva Lestari, 3(1), 9-20.

Asthon, E.C., Hogarth, P.J. \& Ormond, R. (1999). Breakdown of mangrove leaf litter in a managed mangrove forest in Peninnsular Malaysia. Hydrobiologia 413, 77-88.

Brown, S. \& Lugo, A.E. (1982). The storage and production of organic matter in tropical forests and their role in the global carbon cycle. Biotropica, 14, 161-187.

Cannel, M. (1995). Forest and the global carbon cycle in the past, present and future. European Forest Institute Report No. 2, Finland.

Ditjen RLPS (Direktorat Jenderal Rehabilitasi Hutan dan Lahan dan Perhutanan Sosial). (2001). Laporan Akhir Pemantauan, Pengendalian dan Evaluasi Pelaksanaan Kegiatan Hutan Kemasyarakatan, SPL OECF INP-22, Proyek Perencanaan, Pembinaan dan Evaluasi Pembanguan Hutan Kemasyarakatan Pusat. Jakarta: Departemen Kehutanan dan PT Wanacipta Lestari.

Ditha R., Isdrajad, S. \& Endang, H. (2014). Potensi estimasi carbon tersimpan pada vegetasi mangrove di wilayah pesisir Muara Gembang Kabupaten Bekasi. Omni Akuatika, 13(19), 85-91.

Farida H., Kamziah, \& Nurulsyda. (2012). Plant diversity and biomass of Maruda Bay Mangroves in Malaysia. Pakistan Journal of Botany, 44, 151-156.

Gunarto. (2004). Konservasi mangrove sebagai pendukung sumber hayati. perikanan pantai. Jurnal Litbang Pertanian, 23(1), 15-21.

Gupta., H. \& Ghose, M. (2014). Community structure, species diversity and aboveground biomass of Dunderband Mangrove Swams. Tropical Ecology, 55(3), 283-303.

Kauffman, J.B. \& Daniel, C. (2012). Protocols for the measurement, monitoring and reporting of structure, biomass, and carbon stocks in mangrove forests. Bogor, Indonesia: CIFOR.

Kitamura, S., Anwar, C., Chaniago, A. \& Baba, S. (1998). Handbook of mangroves in Indonesia. Bali and Lombok. Jakarta: Ministry of Forestry Indonesia and Japan International Cooperation Agency.

Komiyama, A., Jin, E.O., \& Sasitorn, P. (2008). Allometry, biomass and productivity of mangrove forest: A Review. Aquatic Botany, 89, 128-137.

Muller-Dombois, D. \& Ellenberg, H. (1974). Aims and methods of vegetation ecology. New York: John Wiley and Sons.

Pribadi, R. (1998). The ecology of mangrove vegetation in Bintuni Bay, Irian Jaya, Indonesia. Scotland: Departement of Biological and Molecular Sciences University of Stirling.

Rafdinal \& Nofrita. (2004). Aspek ekologi kepiting bakau (Scylla serrata) di kawasan hutan mangrove Peniti kalimantan Barat. Laporan Penelitian Universitas Tanjungpura.

Rafdinal, Rizalinda, \& Minsas, S. (2016). Perubahan kerapatan dan biomasa tegakan mangrove dalam kaitanya dengan stoks karbon di kawasan pesisir Peniti Kalimantan Barat. Laporan Penelitian Universitas Tanjungpura.

Richter, D.D., Markewitz, D. Dunsomb, J.K., Wells, C.G., Stuanes, A., Allen, H.L., et al. (1995). Carbon cycling in a loblobby pine forest: Implication for the missing carbon sink and for the concept of soil. pp. 223-251. In: W.W. McFee \& J.L. Kelly (eds.) Carbon forms and function in forest soils. Soil Science Society of America, Madison, WI.

Rusila, N.Y., Khazali, M. \& Suryadiputra, I.N.N. (1999). Panduan pengenalan mangrove di Indonesia. Bogor: PHKA/WI-IP. 
Schroeder, P. (1992). Carbon storage potential of short rotation tropical tree plantations. Forest Ecology and Management, 50, 31-41.

Tang, M., Nur, A.I. \& Ramli, M. (2016). Studi kondisi ekosistem mangrove dan produksi detritus di pesisir Kelurahan Lalowaru Kecamatan Moramo Utara Kabupaten Konawe Selatan. Jurnal Manajemen Sumber Daya Perairan, 1(4), 439-450.

Tomlison, P.B. (1994). The botany of mangrove. Cambridge: Cambridge University Press.

Ulqodry, Z. (2008). Produktivitas serasah mangrove dan potensi kontribusi unsur hara di perairan Tanjung Api-Api Sumatera Selatan. [Tesis]. Bogor: Institut Pertanian Bogor.

Zamroni, Y. \& Rohyani, I.S. (2008). Produksi serasah hutan mangrove di perairan Pantai Teluk Sepi, Lombok Barat. Jurnal Biodiversitas, 9(4), 284287. 